\title{
ANALYSIS OF POSSIBILITY LIMITING THE TIME OF TEST INJECTOR IN DIESEL ENGINE USING FACTORY TEST BENCH PRODUCERS OF THESE ELEMENTS
}

\author{
Witold Bąk, Grzegorz Wojnar \\ Silesian University of Technology, Faculty of Transport, \\ Department of Automotive Vehicle Construction \\ Krasińskiego Street 8, 40-019 Katowice, Poland \\ tel.: +4832 6034193, fax: +48326034118 \\ e-mail:witobak@gmail.com,grzegorz.wojnar@polsl.pl
}

\begin{abstract}
Regeneration of parts is the most correct form of use of worn out components and contributes, among others, to reduce $\mathrm{CO}_{2}$ emissions. In the case of elements of fuel injector systems, very high precision is required and such regeneration should be carried out using the original parts. It also requires testing on the original testing stands of these manufacturers, which very often characterized by the fact that it is not possible to perform a short test, which means that it is only possible to perform a time-consuming comprehensive test. An unquestionable advantage in some cases would be the possibility of preliminary verification of the correct operation of the regenerated subassembly without the need for a full time-consuming test. In the present situation, only after completing a time-consuming comprehensive test of the diagnosed element of the injection system, it is often necessary to carry out its disassembly, replacement or correction of one of the components and reassembly with the next time-consuming test. In the case of low unemployment in the labour market, this is extremely unfavourable, and it is often not possible to organize work in such a way that the diagnostic test of the subassembly takes place without the participation of an employee. On the basis of the analyses presented in this article, carried out in the research and development department in company whose employee is one of the co-authors, it can be stated that in the current situation on the labour market where skilled workers are required to work and for the development of science is the most purposeful recognition of the possibility of using vibroacoustic signals to shorten time of tests, which with a high probability may end in a negative result. The preliminary analysis carried out, show that limitation of diagnostic time can be over $35 \%$.
\end{abstract}

Keywords: transport, road transport, simulation, combustion engines, air pollution, environmental protection

\section{Introduction}

On the scale of a large enterprise dealing with the regeneration of components of the power supply systems of Diesel engines, one of the major problems becomes the minimization of the time of diagnosing regenerated mechatronic systems. The companies dealing with the regeneration of spare parts may have different strategies to carry out this process and in some cases; the only criterion is the minimum basket of regeneration and the maximum profit of the company. However, there are also companies whose strategy from the beginning of the uprising is the rebuilding of components only with the participation of original parts of subassembly manufacturers and testing on the original research stations of these manufacturers. In addition, the authorization of many global manufacturers of car parts such as Bosch Diesel Center, Delphi, VDO, Bosch Mahle Turbo Systems, Borg Warner, Gea. The original test stands are very often characterized by the fact that it is not possible to perform a short test, which means that it is only possible to perform a time-consuming comprehensive test. An unquestionable advantage in some cases would be the possibility of preliminary verification of the correct operation of the regenerated subassembly without the need for a full time-consuming test. In the present situation, only after completing a time-consuming comprehensive test of the diagnosed element of the injection system, it is often necessary to carry out its disassembly, replacement or correction of one 
of the components and reassembly with the next time-consuming test. In the case of low unemployment in the labour market, this is extremely unfavourable, and it is often not possible to organize work in such a way that the diagnostic test of the subassembly takes place without the participation of an employee. Based on the previous research of the research and development department of the company of one of the companies recognized on the market, it is advisable to recognize the possibility of using vibroacoustic signals in the initial stage of performing bench tests of injection system components. For this reason, in addition to the standard authorized regeneration of components are also carried out on parallel lines or temporarily excluded from the standard regeneration process works conducted by the research and development department and oriented on the possibility of shortening the time of regeneration and analysis of the results of work carried out together with representatives of car parts manufacturers to consider in the future of possible changes to authorized procedures. The solutions developed by the R \& D department would create an opportunity to interrupt in the initial phase of the test, the result of which would be very negative on the basis of the developed system. After obtaining the consent of the manufacturer of diagnostic parts and systems, the implementation of such an additional diagnostic system on the scale of even one enterprise would generate significant time savings and would result in a much more effective use of diagnostic stands. In addition, it would result in an increase in the number of remanufactured products at the same time, which would contribute to an increase in production efficiency.

Analysing the literature on the presented topic, one can see that ways to reduce repair costs are sought $[5,6]$. Research is conducted on the use of vibroacoustic methods to diagnose car components [1, 2, 7], as well as faults not detected by OBD systems [4]. The methods of artificial intelligence are also used to analyse vibroacoustic signals [3].

\section{Test bench being the subject of analysis}

Two injector models were selected for the tests. Injectors A are installed in in-line six-cylinder Diesel engines of commercial vehicles. These motors with power from 300 to $375 \mathrm{~kW}$ have a displacement of $12.9 \mathrm{dm}^{3}$. On the European market, it is present in fuel systems that meet the Euro 5 standard and can meet the Euro VI standard. Injectors B are also installed in in-line six-cylinder Diesel engines of commercial vehicles. On the European market, it meets Euro 4, Euro 5 and Euro 6 fuel systems and has a capacity of $12.8 \mathrm{dm}^{3}$.

The test bench shown in Fig. 1 enables diagnostics of both models of the injectors analysed.

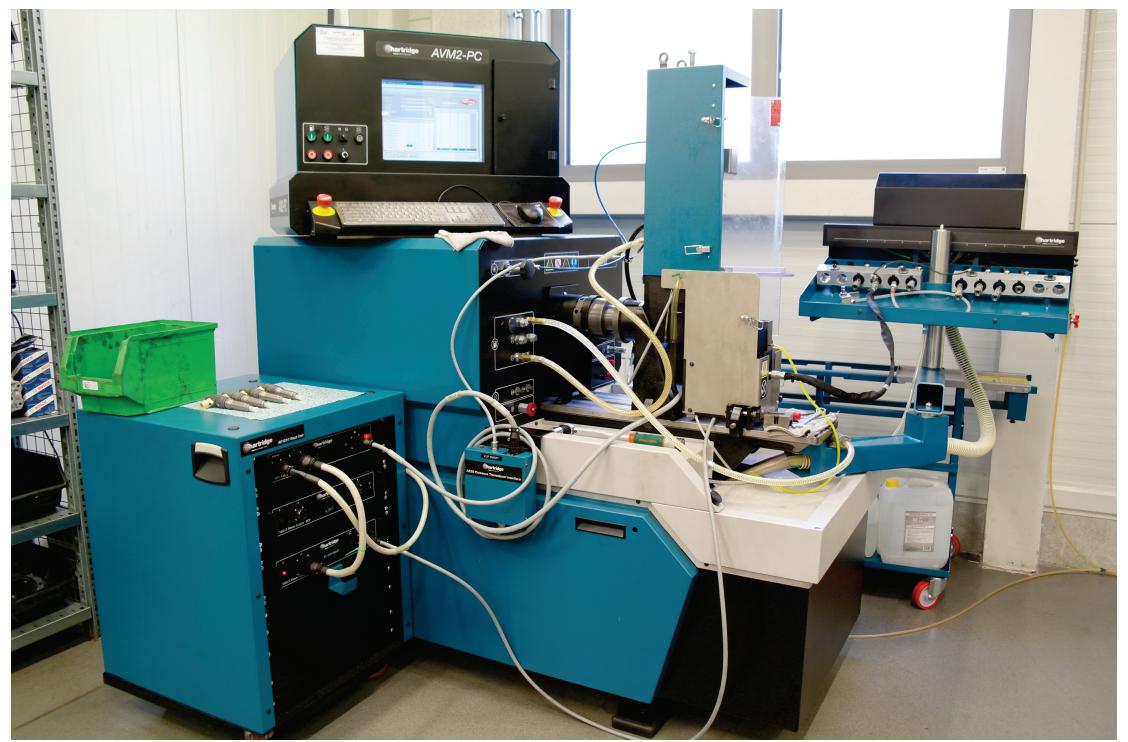

Fig. 1. The AVM2-PC diagnostics 


\section{Result of analysis}

The diagram shown in Fig. 2 illustrates the steps necessary to carry out the regeneration of the injector and the times of performing individual operations.

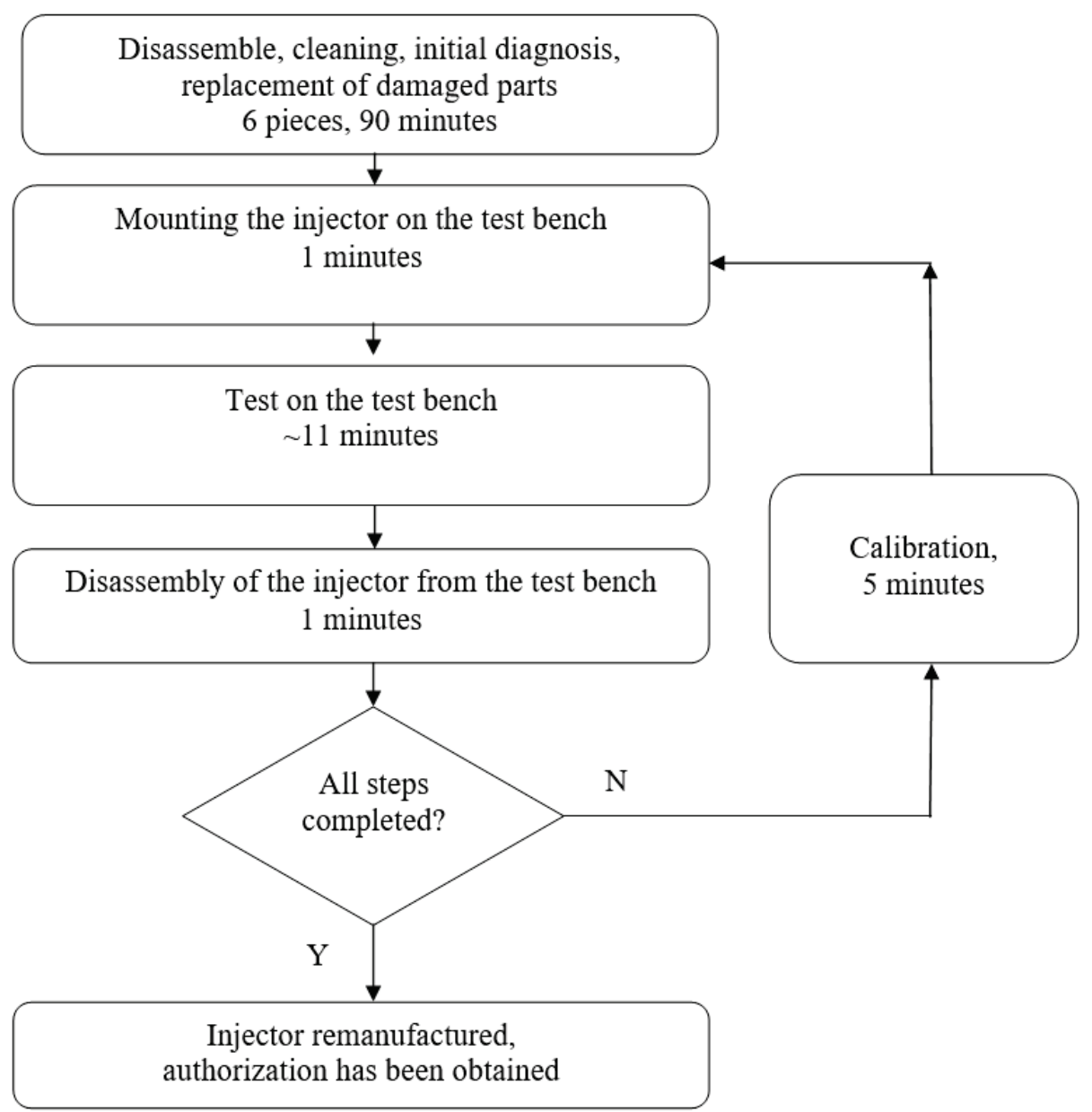

Fig. 2. Diagram showing the steps necessary to carry out the regeneration of the injector and the times of performing individual operations

Table 1 presents the comparison of the execution times of individual activities in the case of both analysed injectors.

Tab. 1. Comparison of activities

\begin{tabular}{|c|l|c|c|}
\hline Item & \multicolumn{1}{|c|}{ Action } & $\begin{array}{c}\text { Injector model “A" } \\
\text { Time: } \times 60[\mathrm{~s}]\end{array}$ & $\begin{array}{c}\text { Injector model "B" } \\
\text { Time: } \times 60[\mathrm{~s}]\end{array}$ \\
\hline 1 & Disassembly, cleaning, assembly & 75 & 90 \\
\hline 2 & Assembly on test bench & 1 & 1 \\
\hline 3 & Diagnostic on test bench & 11.5 & 10.5 \\
\hline 4 & Disassembly & 1 & 1 \\
\hline 5 & Calibration & 5 & 5 \\
\hline 6 & $\begin{array}{l}\text { Assembly on test bench, diagnostic, disassembly } \\
\text { (sum of activities 2, 3 and 4) }\end{array}$ & 13.5 & 12.5 \\
\hline
\end{tabular}

Table 2 shows the total time of all activities performed with a different number of possibly necessary repetitions of the activities shown in Fig. 2. Practice shows that in order to regenerate 
one injector statistically it is required to perform 4 repetitions of the above operations. For this reason, the situation was compared when in each repetition the injector manufacturer's authorized test was used. A short test based on vibroacoustic signals but ended with an authorized test. It has been assumed that the abridged test will last up to two minutes and if there is a high probability of the negative test being completed, it will be discontinued after the said 3 minutes. The presented reduction of time results from the initial experience of the author of this publication based on work in the research and development department of one of the companies dealing with the regeneration of injectors. The time given was measured during experimental work, and the diagnosis was based on the subjective acoustic feelings of an experienced device operator with many years of experience in servicing this type of station. The use of this expert knowledge in the form of registration of vibroacoustic signals and their analysis would allow automating this form of the short test in the future and thus possibly more efficient use of the time of work of a qualified employee with many years of experience.

The Tab. 3 shows analogous results but for injector "B".

Tab. 2. Injector "A" proposed solution, comparison of testing time

\begin{tabular}{|l|c|c|c|c|c|}
\hline \multicolumn{1}{|c|}{ Number of repetitions } & 1 & 2 & 3 & 4 & 5 \\
\hline $\begin{array}{l}\text { Assembly on test bench, short test based on vibroacoustic signals, } \\
\text { disassembly } \mid \times 60[\mathrm{~s}]\end{array}$ & 5 & 10 & 15 & 20 & 25 \\
\hline Assembly on test bench, authorized diagnostic, disassembly $\mid \times 60[\mathrm{~s}]$ & 13.5 & 27 & 40.5 & 54 & 67.5 \\
\hline $\begin{array}{l}\text { Total time if the test is successful in this repetition } \\
\text { and the short test has not been used } \mid \times \mathbf{6 0}[\mathbf{s}]\end{array}$ & $\mathbf{1 3 . 5}$ & $\mathbf{3 2}$ & $\mathbf{5 0 . 5}$ & $\mathbf{6 9}$ & $\mathbf{8 7 . 5}$ \\
\hline $\begin{array}{l}\text { Total time if the test is successful in this repetition and the } \\
\text { abbreviated test was used in this and previous replications } \mid \times \mathbf{6 0}[\mathbf{s}]\end{array}$ & $\mathbf{1 3 . 5}$ & $\mathbf{2 3 . 5}$ & $\mathbf{3 3 . 5}$ & $\mathbf{4 3 . 5}$ & $\mathbf{5 3 . 5}$ \\
\hline Calibration $\mid \times 60[\mathrm{~s}]$ & 5 & 5 & 5 & 5 & 5 \\
\hline $\begin{array}{l}\text { Saving time if the test has not been successfully completed } \\
\text { in this repetition } \mid \times 60[\mathrm{~s}]\end{array}$ & 0 & 8.5 & 17 & 25.5 & 34 \\
\hline
\end{tabular}

Tab. 3. Injector “ $B$ ” proposed solution - comparison of testing time

\begin{tabular}{|l|c|c|c|c|c|}
\hline \multicolumn{1}{|c|}{ Number of repetitions } & 1 & 2 & 3 & 4 & 5 \\
\hline $\begin{array}{l}\text { Assembly on test bench, short test based on vibroacoustic signals, } \\
\text { disassembly } \mid \times 60[\mathrm{~s}]\end{array}$ & 5 & 10 & 15 & 20 & 25 \\
\hline Assembly on test bench, authorized diagnostic, disassembly $\mid \times 60[\mathrm{~s}]$ & 12.5 & 25 & 37.5 & 50 & 62.5 \\
\hline $\begin{array}{l}\text { Total time if the test is successful in this repetition } \\
\text { and the short test has not been used } \mid \times \mathbf{6 0}[\mathbf{s}]\end{array}$ & $\mathbf{1 2 . 5}$ & $\mathbf{3 0}$ & $\mathbf{4 7 . 5}$ & $\mathbf{6 5}$ & $\mathbf{8 2 . 5}$ \\
\hline $\begin{array}{l}\text { Total time if the test is successful in this repetition and the } \\
\text { abbreviated test was used in this and previous replications } \mid \times \mathbf{6 0}[\mathbf{s}]\end{array}$ & $\mathbf{1 2 . 5}$ & $\mathbf{2 2 . 5}$ & $\mathbf{3 2 . 5}$ & $\mathbf{4 2 . 5}$ & $\mathbf{5 2 . 5}$ \\
\hline Calibration $\mid \times 60[\mathrm{~s}]$ & 5 & 5 & 5 & 5 & 5 \\
\hline $\begin{array}{l}\text { Saving time if the test has not been successfully completed } \\
\text { in this repetition } \mid \times 60[\mathrm{~s}]\end{array}$ & 0 & 7.5 & 15 & 22.5 & 30 \\
\hline
\end{tabular}

Figures 3 and 4 show for injectors A and B time-consuming work relationships with several authorized tests and short tests based on expert knowledge of an experienced employee. It also illustrates the time savings resulting from the possible application of the test in the experimental work, which is likely to end in a negative result. It should be noted that in the case of both tests, the injector will finally pass the authorized test and its time in has been included in the time savings calculations. 


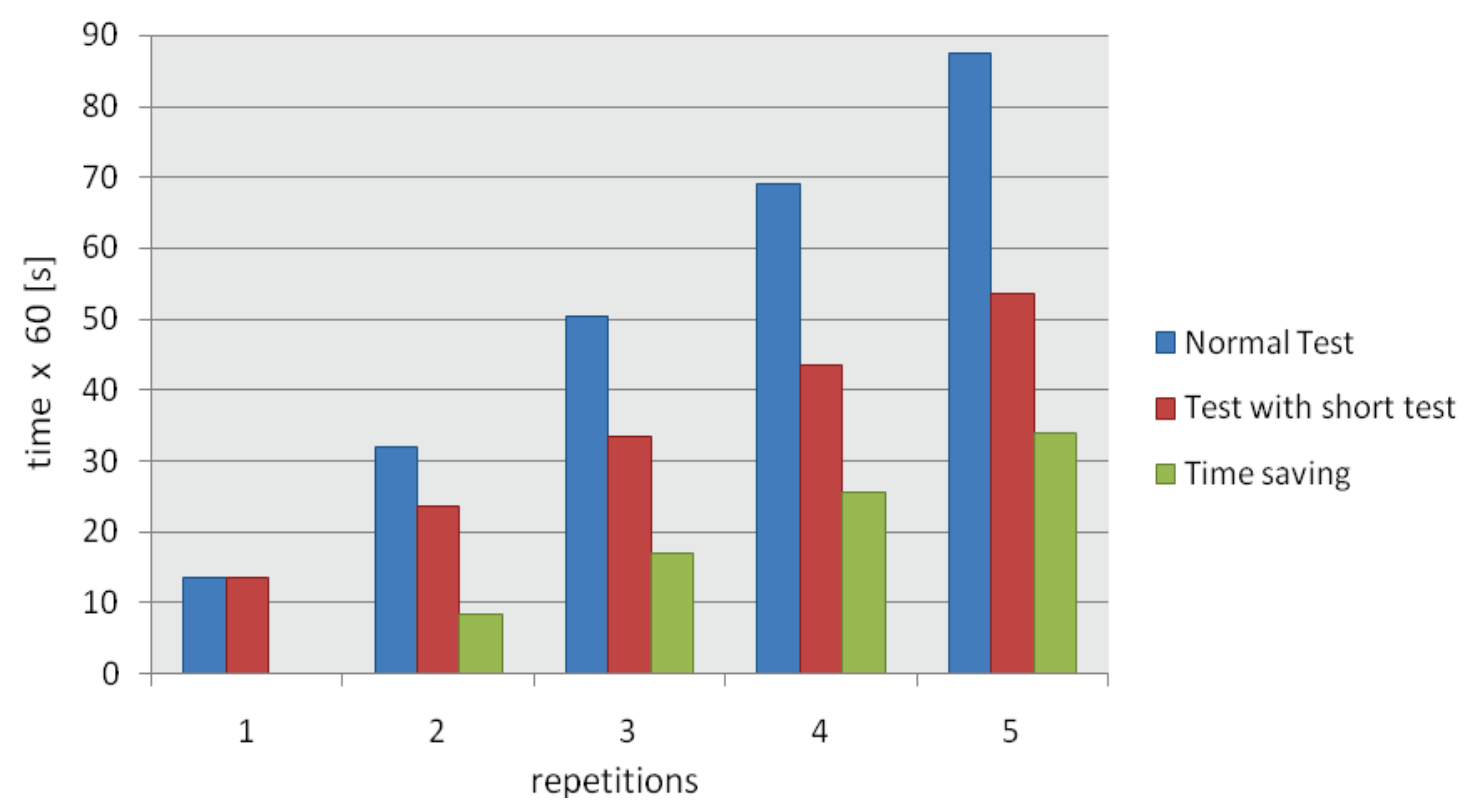

Fig. 3. Summary of the time of full regeneration of the injector A and number of repetition cycles using test with a short diagnostic test

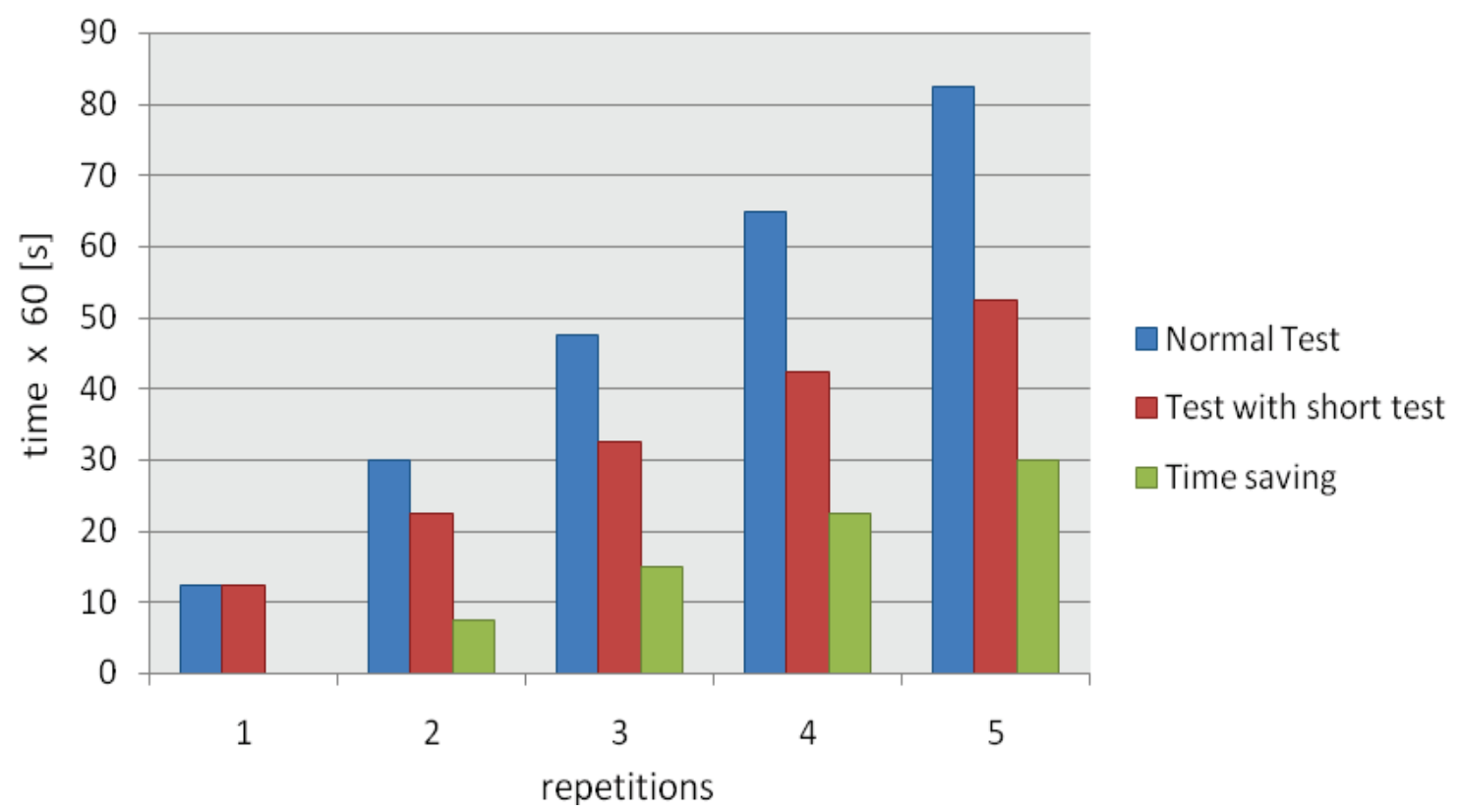

Fig. 4. Summary of the time of full regeneration of the injector $B$ and number of repetition cycles using a short diagnostic test

\section{Summary and conclusions}

Based on the analysis carried out, the following conclusions can be made:

1) In the current situation on the labour market, where qualified employees are required to work and for the development of science is the most purposeful identification of the use of vibroacoustic signals, in particular acoustic pressure, to shorten the test time, which with a high probability may end in a negative result.

2) Preliminary analyses show that the time reduction for injector A can be around $37 \%$ for the fourth attempt, and for the injector B the diagnostic time limit is 35\% also for the averaged fourth test.

3) The next stage of work will be the analysis of recorded vibroacoustic signals. 


\section{References}

[1] Albarbar, A., An investigation into diesel engine air-borne acoustics using continuous wavelet transform, Journal of Mechanical Science and Technology, Vol. 27, Iss. 9, pp. 2599-2604, 2013.

[2] Albarbar, A., Gu, F., Ball, A. D., Diesel engine fuel injection monitoring using acoustic measurements and independent component analysis, Measurement: Journal of the International Measurement Confederation, Vol. 43, Iss. 10, pp. 1376-1386, 2010.

[3] Czech, P., Vibroacoustic signals in transport. Positive and negative effects of occurrence, Publishing House of the Silesian University of Technology, Gliwice 2018.

[4] Dąbrowski, Z., Zawisza, M., Investigations of the vibroacoustic signals sensitivity to mechanical defects not recognised by the OBD system in diesel engines, Solid State Phenomena, Vol. 180, pp. 194-199, 2012.

[5] Droździel, P., Komsta, H., Krzywonos, L., An analysis of costs of vehicle repairs in a transportation company, part 1, Transport Problems, Vol. 7, Iss. 3, pp. 67-75, 2012.

[6] Droździel, P., Komsta, H., Krzywonos, L., An analysis of costs of vehicle repairs in a transportation company, part 2, Transport Problems, Vol. 7, Iss. 4, pp. 7-11, 2012.

[7] Kałuża, R., Czech, P., Folęga, P., Selection of vibro-acoustic sensors to diagnostic systems for car engines, Transport Systems. Theory and Practice TSTP2016. 13th Scientific and Technical Conference, Katowice, September 19-21, 2016.

Manuscript received 09 September 2019; approved for printing 19 December 2019 